\title{
PENGARUH STRATEGI BAURAN PEMASARAN TERHADAP PENINGKATAN PENJUALAN PADA PRODUK DR. KEBAB BARA SATRIYA SIDOARJO
}

\author{
Nur Achmad Rofi'i', Didin Fatihudin² \& Mochamad Mochklas ${ }^{3}$ \\ 1,2,3 Universitas Muhammadiyah Surabaya
}

\begin{abstract}
DR. KEBAB Bara Satriya is one of the fast food businesses in Sidoarjo regency. The purpose of this research is to find out which of the variables (product, price, promotion, place) has a dominant influence on the increase in sales of DR. KEBAB Bara Satriya, and to find out whether marketing strategies (marketing mix) have a simultaneous influence on increasing sales of DR. KEBAB Bara Satriya.

The method of approach to this research is a quantitative approach, the technique of collecting data with questionnaires and the sampling technique used is accidental sampling with a total of 60 respondents. The analytical method used is the method of multiple linear regression analysis using the normality test, hypothesis testing, F test, and test. The data processed using the SPSS program produces the following regression equation: $Y=6.685+0.290 X 1+(-0.266 X 2)+$ $0.462 X 3+0.364 X 4+e$. Based on hypothesis testing the results of the $F$ test show that the marketing mix independent variables which include products, prices, promotions and places of influence simultaneously on increasing sales. While the t test shows that promotion is a variable that has a dominant influence on increasing sales.
\end{abstract}

$\begin{array}{ll}\text { Keywords } & : \text { Marketing Mix, Increased Sales } \\ \text { Correspondence to } & : \text { mmochklas@gmail.com }\end{array}$

\begin{abstract}
ABSTRAK
DR. KEBAB Bara Satriya merupakan salah satu bisnis makanan cepat saji yang terdapat di kabupaten Sidoarjo. Tujuan dari peneltian ini untuk mengetahui manakah dari variabel (product, price, promotion, place) yang berpengaruh dominan terhadap peningkatan penjualan produk DR. KEBAB Bara Satriya, dan untuk mengetahui apakah strategi pemasaran (marketing mix) berpengaruh secara simultan terhadap peningkatan penjualan produk DR. KEBAB Bara Satriya.

Metode pendekatan penelitian ini adalah pendekatan kuantitatif, teknik pengumpulan datanya dengan kuesioner dan teknik sampling yang digunakan adalah accidental sampling dengan jumlah 60 responden. Metode analisis yang digunakan adalah metode analisis regresi linier berganda dengan menggunakan uji normalitas, uji hipotesis, uji $\mathrm{F}$, dan uji t. Data-data diolah dengan menggunakan program SPSS menghasilkan persamaan regresi sebagai berikut : $\mathrm{Y}=6,685+$ $0,290 \mathrm{X}_{1}+\left(-0,266 \mathrm{X}_{2}\right)+0,462 \mathrm{X}_{3}+0,364 \mathrm{X}_{4}+e$. Berdasarkan pengujian hipotesis hasil uji $\mathrm{F}$ menunjukkan bahwa variabel bebas bauran pemasaran yang meliputi produk, harga, promosi dan
\end{abstract}


tempat berpengaruh secara simultan terhadap peningkatan penjualan. Sedangkan uji t menunjukkan bahwa promosi adalah variabel yang berpengaruh secara dominan terhadap peningkatan penjualan.

Kata kunci Korespondensi

\author{
: Bauran Pemasaran, Peningkatan Penjualan \\ :mmochklas@gmail.com
}

\section{PENDAHULUAN / INTRODUCTION}

Bisnis kuliner adalah bisnis yang sedang digandrungi para pengusaha saat ini. Para pengusaha melirik ini dikarenakan makanan adalah hal utama yang dibutuhkan manusia untuk hidup. Bisnis kuliner bisa juga disebut bisnis yang tidak ada matinya. Bertambahnya kesibukan dan tingkat aktivitas seseorang, maka setiap orang membutuhkan sesuatu yang cepat dan instan. Makanan cepat saji tidak memerlukan waktu yang lama dalam hal penyajian kepada konsumen. Contohnya di Kabupaten Sidoarjo, di sana kita sangat mudah untuk menemukan pengusaha-pengusaha yang menjalankan bisnis kuliner terutama makanan cepat saji. Baik di sudut kota maupun disepanjang jalan protokoler banyak berjejer usaha kuliner mulai dari tenda-tenda pedagang kaki lima, cafe, restaurant/rumah makan, hingga resto di mall. Penyajian makanan yang sehat, halal, dan memiliki citarasa yang khas, dan dijajakan dengan harga terjangkau tentu sangat diminati bagi semua kalangan masyarakat.

Salah satu bisnis makanan cepat saji yang terdapat di kabupaten Sidoarjo ini adalah DR. KEBAB Bara Satriya yang berpusat di Jl. Garuda no. 48B adalah usaha yang berawal dari pengalaman kerja beliau sebelumnya dan ditunjang dengan hobi memasaknya. Nama DR. KEBAB Bara Satriya diambil dari nama Wahyu Bagus Satrio yakni sang pemilik sendiri. Nama tersebut sang pemilik cetuskan secara spontan. DR. KEBAB Bara Satriya menawarkan beberapa jenis makanan dengan harga yang sangat terjangkau.

DR. KEBAB Bara Satriya ini berada di daerah Kepuh, Betro, Sidoarjo berdiri sejak tahun 2013 sampai sekarang. Lokasi usaha yang strategis yaitu dipemukiman warga dan ditambah lagi di pinggir jalan, sehingga pangsa pasar atau mayoritas konsumen adalah masyarakat sekitar dan orang-orang yang melintas di jalan tersebut. Tidak ada ciri khas yang menonjol dari produk yang ditawarkan DR. KEBAB Bara Satriya ini. Dari masa ke masa DR. KEBAB Bara Satriya senantiasa menambah variasi pada produknya agar konsumen tidak bosan dengan produk yang ditawarkan.

Keberhasilan suatu usaha dapat dilihat dari bagaimana usaha tersebut mampu memasarkan produk yang berkualitas dengan harga terjangkau sehingga membuat konsumen berminat dan tertarik untuk melakukan pembelian. Untuk dapat menarik konsumen agar membeli produk yang dihasilkan, maka suatu usaha harus mampu merumuskan strategi pemasaran seperti apa yang akan digunakan. Strategi pemasaran dalam suatu usaha merupakan suatu rencana keseluruhan untuk mencapai tujuan yang telah ditetapkan.

\section{METODE PENELITIAN / METHODS}

Metode penelitian ini menggunakan penelitian kuantitatif menggunakan analisis regresi linier berganda, program SPSS 
(Statistical Product and Service Solution) versi 25.

Pendekatan penelitian yang digunakan oleh penulis adalah menggunakan metode kuantitatif. Jenis data yang digunakan dalam penelitian ini adalah data kuantitatif berupa kuisioner, sedangkan data yang digunakan data primer yang dilakukan dengan pengumpulan sendiri oleh peneliti secara langsung dari objek penelitian, (Fatihudin 2012 : 98).

Variabel yang digunakan dalam penelitian ini dikelompokkan menjadi dua yaitu variabel bebas dan variabel terikat. Variabel bebas dalam penelitian ini adalah Product, Price, Promotion, Place dan variabel terikat dalam penelitian ini adalah Peningkatan Penjualan.

Jumlah sampel dalam penelitian ini adalah 60 responden. Metode pengambilan sampel dalam penelitian ini menggunakan metode non probability sampling dan teknik yang digunakan adalah convenience sampling atau juga bisa disebut dengan accidental sampling.

\section{HASIL PENELITIAN / RESULTS}

\section{Uji Validitas}

Dari tabel hasil uji validitas, pada masing-masing butir soal nilai Rhitung> Rtabel $(0,2542)$ sehingga data yang diperoleh dari penelitian menunjukkan bahwa setiap butir soal pada masing-masing variabel dapat dinyatakan valid.

\section{Uji Reliabilitas}

Nilai crobanch's alpha variabel Produk $(0,703)$, Harga $(0,728)$, Promosi $(0,783)$, Tempat (0,710), Peningkatan Penjualan $(0,792)$ lebih besar dari 0,60 sehingga dapat dikatakan data tersebut reliabel.

\section{Uji F (ANOVAa)}

TABEL 1: Hasil Uji Anova A

\begin{tabular}{|l|r|r|r|c|c|}
\hline Model & $\begin{array}{r}\text { Sum of } \\
\text { Squares }\end{array}$ & df & $\begin{array}{c}\text { Mean } \\
\text { Square }\end{array}$ & F & Sig. \\
\hline Regression & 65.570 & 4 & 16.393 & 20.415 & $.000^{\mathrm{a}}$ \\
Residual & 44.163 & 55 & .803 & & \\
Total & 109.733 & 59 & & & \\
\hline
\end{tabular}

a. Dependent Variable: Peningkatan Penjualan

b. Predictors: (Constant), Tempat, Harga, Promosi, Produk

Sumber : Data Primer (2019)

Dari tabel analisa hasil uji $\mathrm{F}$ diatas, terlihat bahwa Fhitung sebesar 20,415 dengan signifikasi 0,000. Sedangkan besarnya Ftabel adalah sebesar 2,54. Dengan demikian terlihat bahwa Fhitung $=20,415>$ Ftabel $=2,54$, sehingga berdasarkan kriteria pengujian uji $\mathrm{F}$, maka Hi diterima dan $\mathrm{H} 0$ ditolak atau dengan kata lain bahwa dugaan yang menyatakan Product, Price, Promotion, Place berpengaruh signifikan terhadap Peningkatan Penjualan Produk DR. KEBAB Bara Satriya.

\section{Uji t}

TABEL 2: Hasil Uji t

\begin{tabular}{|c|c|c|c|c|c|}
\hline \multirow{2}{*}{ Model } & \multicolumn{2}{|c|}{$\begin{array}{c}\text { Unstandardized } \\
\text { Coefficients } \\
\end{array}$} & \multirow{2}{*}{\begin{tabular}{|c|}
$\begin{array}{c}\text { Standardized } \\
\text { Coefficients }\end{array}$ \\
Beta
\end{tabular}} & \multirow{2}{*}{$\mathrm{t}$} & \multirow{2}{*}{ Sig. } \\
\hline & B & $\begin{array}{l}\text { Std. } \\
\text { Error }\end{array}$ & & & \\
\hline 1 (Constant) & 6,685 & 1,242 & & 5.384 & .000 \\
\hline Produk & ,290 & ,113 & 317 & 2,559 & .013 \\
\hline Harga &,- 266 & , 112 &,- 267 & $-2,366$ & .022 \\
\hline Promosi & ,462 &, 165 &, 381 & 2,805 & .007 \\
\hline Tempat &, 364 & , 143 &, 333 & 2.553 & .013 \\
\hline
\end{tabular}

a. Dependent Variable: Peningkatan Penjualan Sumber : Data Primer (2019)

Dalam penelitian ini pengujian parsial (uji t) digunakan untuk mengetahui apakah variabel bebas Produk(X1), Harga(X2), Promosi (X3) dan Tempat (X4) secara parsial berpengaruh terhadap Peningkatan Penjualan (Y)

Berdasarkan uji $\mathrm{T}$ dapat diperoleh pada variabel Produk menunjukkan nilai 
perbandingan Thitung dengan Ttabel adalah $2.559>2.004$ dengan nilai signifikansi 0,013 $>0,05$. Maka dapat disimpulkan bahwa variabel produk berpengaruh positif signifikan secara parsial terhadap peningkatan penjualan. Hasil perhitungan uji $\mathrm{T}$ variabel harga menunjukkan nilai perbandingan Thitung dengan Ttabel adalah $2.366>2.004$ dengan nilai signifikansi 0,022 $>0,05$. Maka dapat disimpulkan bahwa variabel harga berpengaruh negatif signifikan secara parsial terhadap peningkatan penjualan. Hasil perhitungan uji $\mathrm{T}$ variabel promosi menunjukkan nilai perbandingan Thitung dengan Ttabeladalah $2.805>2.004$ dengan nilai signifikansi $0,07>0,05$. Maka dapat disimpulkan bahwa variabel promosi berpengaruh positif signifikan secara parsial terhadap peningkatan. Hasil perhitungan uji T variabel tempat menunjukkan nilai perbandingan Thitung dengan Ttabel adalah $2.553>2.004$ dengan nilai signifikansi 0,013 $>0,05$. Maka dapat disimpulkan bahwa variabel tempat berpengaruh positif signifikan secara parsial terhadap peningkatan penjualan.

Berdasarkan uji $\mathrm{T}$ dapat disimpulkan bahwa variabel promotion yang berpengaruh secara dominan terhadap peningkatan penjualan produk DR. KEBAB Bara Satriya.

\section{Regresi Linear Berganda}

\section{TABEL 3: Hasil Regresi Linier Berganda}

\begin{tabular}{|c|c|c|c|c|c|}
\hline \multirow{2}{*}{ Model } & \multicolumn{2}{|c|}{$\begin{array}{l}\text { Unstandardized } \\
\text { Coefficients }\end{array}$} & \multirow{2}{*}{\begin{tabular}{|c|}
$\begin{array}{c}\text { Standardized } \\
\text { Coefficients }\end{array}$ \\
Beta
\end{tabular}} & \multirow{2}{*}{$\mathrm{t}$} & \multirow{2}{*}{ Sig. } \\
\hline & B & $\begin{array}{l}\text { Std. } \\
\text { Error }\end{array}$ & & & \\
\hline 1 (Constant) & 6,685 & 1,242 & & 5.384 & .000 \\
\hline Produk & ,290 &, 113 & ,317 & 2,559 & .013 \\
\hline Harga &,- 266 &, 112 &,- 267 & $-2,366$ & .022 \\
\hline Promosi & ,462 &, 165 & ,381 & 2,805 & .007 \\
\hline Tempat & ,364 & , 143 & ,333 & 2.553 & .013 \\
\hline
\end{tabular}

a. Dependent Variable: Peningkatan Penjualan Sumber : Data Primer (2019)

$$
\begin{aligned}
& Y=\alpha+\beta_{1} X_{1}+\beta_{2} X_{2}+\beta_{3} X_{3}+\beta_{4} X_{4}+e \\
& Y=6,685+0,290 X_{1}+\left(-0,266 X_{2}\right)+0,462 X_{3}+0,364 X_{4}+e
\end{aligned}
$$

\section{Uji Koefisien Determinasi (R2)}

\begin{tabular}{|c|c|c|c|c|}
\hline Model & $\mathrm{R}$ & $\begin{array}{c}\mathrm{R} \\
\text { Square }\end{array}$ & $\begin{array}{c}\text { Adjusted R } \\
\text { Square }\end{array}$ & $\begin{array}{c}\text { Std. Error } \\
\text { of the } \\
\text { Estimate }\end{array}$ \\
\hline 1 & $.773^{\mathrm{a}}$ & .598 & .568 & .896 \\
\hline
\end{tabular}

TABEL 4: Hasil Uji Koefisien Determinasi (R2)

Dari tabel diatas diketahui bahwanilai koefisien determinasi berganda (R-square) adalah 0,598 atau $59,8 \%$. Nilai ini menunjukkan bahwa 59,8\% Peningkatan Penjualan (Y) dipengaruhi oleh Produk(X1), Harga(X2), Promosi(X3), Tempat(X4) dan sisanya $40,2 \%$ dipengaruhi oleh variabel lain diluar penelitian.

\section{PEMBAHASAN / DISCUSSION}

1)Produk (Product) Terhadap Peningkatan Penjualan Produk DR. KEBAB Bara Satriya. Produk yaitu sebuah barang atau jasa yang ditunjukkan kepada konsumen melalui pemuasan kebutuhan dan keinginan pelanggan. Produk disini biasa berupa apa saja (baik yang berwujud fisik maupun tidak) yang dapat ditawarkan kepada pelanggan potensial untuk memenuhi kebutuhan dan keinginan tertentu. Sesuatu yang dapat ditawarkan ke pasar untuk diperhatikan, dimiliki, atau dikonsumsi sehingga dapat memuaskan keinginan dan kebutuhan, Sudaryono (2016). Koefisien regresi produk sebesar 0,290 menyatakan bahwa produk berpengaruh terhadap peningkatan penjualan. Hasil uji $\mathrm{T}$ juga didapat perbandingan antara Thitung 2,559 > Ttabel 2,004 dapat disimpulkan bahwa produk secara parsial berpengaruh positif signifikan terhadap peningkatan penjualan produk DR. KEBAB 
Bara Satriya. Hal ini sejalan dengan penelitian Nurcahyo (2016) bahwa produk berpengaruh parsial terhadap peningkatan penjualan.

Harga (Price) Terhadap Peningkatan Penjualan Produk DR. KEBAB Bara Satriya.

2)Harga yaitu Harga adalah sejumlah uang yang berfungsi sebagai alat tukar untuk memperoleh produk atau jasa. Harga adalah suatu nilai tukar yang bisa disamakan dengan uang atau barang lain untuk manfaat yang diperoleh dari suatu barang atau jasa bagi seseorang atau kelompok atau individu pada waktu dan tempat tertentu, Deliyanti (2012). Koefisien regresi harga sebesar -0,266 menyatakan bahwa harga dapat berpengaruh terhadap peningkatan penjualan. Hasil uji $\mathrm{T}$ juga didapat perbandingan antara Thitung 2,366 > 2,004 dapat disimpulkan bahwa harga secara parsial berpengaruh negatif signifikan terhadap peningkatan penjualan Produk DR. KEBAB Bara Satriya. Hal ini didukung oleh penelitian Salindeho (2014) bahwa harga berpengaruh secara parsial terhadap peningkatan penjualan.

3) Promosi (Promotion) Terhadap Peningkatan Penjualan Produk DR. KEBAB Bara Satriya. Promosi yaitu suatu kegiatan pemasaran yang digunakan untuk menyebarkan informasi, mempengaruhi, membujuk, atau mengingatkankan kepada konsumen agar bersedia menerima, membeli, dan loyal kepada produk yang ditawarkan perusahaan tersebut, Harman Malau (2016). Koefisien regresi promosi sebesar 0,462 menyatakan bahwa promosi berpengaruh terhadap peningkatan penjualan. Hasil uji $\mathrm{T}$ juga didapat perbandingan antara Thitung 2,850 > 2,004 sehingga dapat disimpulkan bahwa promosi berpengaruh secara positif signifikan terhadap peningkatan penjualan produk DR. KEBAB Bara Satriya. Disamping itu promosi juga berpengaruh secara dominan terhadap peningkatan penjualan produk DR. KEBAB Bara Satriya karena memiliki nilai tertinggi diantara variable yang lain. Hal ini didukung oleh penelitian Malik (2015) bahwa promosi berpengaruh dominan terhadap peningkatan penjualan.

4) Saluran distribusi/tempat (Place) Terhadap Peningkatan Penjualan Produk DR. KEBAB Bara Satriya.

Tempat yaitu lembaga - lembaga yang memasarkan produk berupa barang atau jasa dari produsen sampai konsumen, Place merupakan keputusan distribusi menyangkut kemudahan untuk mengakses produk atau jasa bagi pelanggan, tempat tersedia di sejumlah saluran distribusi dan outlet yang dapat ditemui oleh banyak konsumen dengan mudah dalam memperoleh produk atau jasa yang diinginkan, Assauri (2010). Koefisien regresi saluran distribusi/ tempat 0,364 menyatakan bahwa secara parsial berpengaruh positif terhadap peningkatan penjualan. Hasil uji $\mathrm{T}$ juga didapat perbandingan antara Thitung 2,553 > 2,004 sehingga dapat disimpulkan bahwa tempat berpengaruh secara parsial terhadap peningkatan penjualan Produk DR. KEBAB Bara Satriya.

\section{KESIMPULAN / CONCLUSSION Simpulan}

Berdasarkan hasil pengujian penelitian dapat ditarik dua kesimpulan untuk menjawab rumusan masalah sebagai berikut:

1. Promosi berpengaruh dominan secara signifikan terhadap peningkatan penjualan produk DR. KEBAB Bara Satriya.

2. Strategi bauran pemasaran (product, price, promotion, place) berpengaruh secara simultan terhadap peningkatan penjualan produk DR. KEBAB Bara Satriya.

Saran

Dari hasil penelitian yang telah dilakukan, maka peneliti mencoba 
memberikan masukan dan saran sebagai berikut:

1. Promosi yang dilakukan DR. KEBAB Bara Satriya saat ini hanya dilakukan pada akun media sosial dan promosi secara langsung/face to face saja. Seharusnya promosi yang dilakukan bisa menggunakan lebih banyak cara lagi untuk melakukan penjualannya. Misalnya dengan mendaftarkan gerainya untuk menjadi Mitra GO-JEK agar masyarakat lebih mudah untuk melihat dan tentunya membeli produk DR. KEBAB Bara Satriya.

2. Sebagaimana diketahui bahwa strategi bauran pemasaran (product, price, promotion, place) merupakan faktor yang berpengaruh terhadap peningkatan penjualan, maka diharapkan pada DR. KEBAB Bara Satriya memperhatikan faktor-faktor tersebut untuk lebih meningkatkan penjualannya

3. Untuk para peneliti selanjutnya peneliti menyarankan untuk lebih memperdalam unit analisisnya, baik dari variabel maupun indikatornya, sehingga dapat lebih mempertajam hasil yang sudah diperoleh peneliti di dalam penelitian ini.

\section{DAFTAR PUSTAKA / BIBLIOGRAPHY}

Aaker, D. (2013). Manajemen Pemasaran Strategi (8 ed.). Jakarta: Salemba Empat.
Abdullah dan Tantri. (2012). Manajemen Pemasaran. Jakarta: Rajawali Pers.

Amir, M. T. (2012). Manajemen Strategik : Konsep dan Aplikasi. Jakarta: PT. Raja Grafindo Persada.

Amstrong, K. (2008). Prinsip-Prinsip Pemasaran (12 ed.). Jakarta: Erlangga.

Assauri, S. (2010). Manajemen Pemasaran, Dasar, Konsep dan Strategi. Jakarta: Raja Grafindo Persada.

Delianti, O. (2012). Manajemen Pemasaran. Yogyakarta. Didin Fatihudin, D., Jusni, \& Mochklas, M. (2018). HOW MEASURING FINANCIAL PERFORMANCE . International Journal of Civil Engineering and Technology (IJCIET), 9(6): 553-557

Fatihudin dan Mochklas. (2017). Analysis of Factors Affecting Consumer Decisions Buy Motorcycle (Study on City of Surabaya Indonesia). International Journal Of Innovative Research \& Development ISSN 2278 - 0211 .

Firmansyah, M.A., \& Mochklas, M. (2018). The Effect of Quality of Interaction, Physical Environment and Quality of Results on the Loyalty of ATHLETIC CLUB in Surabaya. Saudi Journal of Business and Management Studies (SJBMS) 3(3): 205- 211

Firmansyah, M.A., \& Mochklas, M. 2018. Analisa Strategi Produk, Harga, Promosi Dan Tempat Terhadap Kepuasan Pelanggan Warung Giras Di Surabaya. Jurnal EKSEKUTIF, 15(1): 281- 295 
Ghozali, I. (2012). Aplikasi Analisis Multivariate Dengan Program SPSS. Semarang: Badan Penerbit Universitas Diponegoro.

Hanifaradiz, A. (2016). Pengaruh Bauran Pemasaran Terhadap Keputusan Pembelian Sabun Mandi Lifebuoy Di Surabaya. Jurnal Ilmu dan Riset Manajemen , 5.

Hasan, Ali. (2013). Marketing dan Kasuskasus Pilihan. Yogyakarta: CAPS.

Karim, D. (2014). Marketing Mix Pengaruhnya Terhadap Volume Ppenjualan Pada PT. Manado Sejati Perkasa Group. Jurnal EMBA, 421.

Kotler , K. (2009). Manajemen Pemasaran. Jakarta: Kencana Prenada Media.

Kotler dan Amstrong. (2008). PrinsipPrinsip Pemasaran. Jakarta: Erlangga.

Kotler dan Susanto. (2002). Manajemen Pemasaran di Indonesia : Analisis, Perencanaan, Implementasi dan Pengendalian. Jakarta: Salemba Empat.

Kotler, P. (2007). Manajemen Pemasaran (12 ed.). Jakrta: PT. Indeks.

Malau, H. (2017). Manajemen Pemasaran. Bandung: CV.Alfabeta.

Malik, N. (2015). Pengaruh Bauran Pemasaran Terhadap Volume Penjualan Notebook Merek Acer Pada CV. Galaksi Komputer Di Samarinda. ejournal Ilmu Administrasi Bisnis , 3, 4.
Mochklas, M. (2017). Analisa Gaya Kepemimpinan Ekspatriat Korea Selatan Dalam Memimpin Perusahaan Di Indonesia. JURNAL EKSEKUTIF, 14(2),241-252

Mochklas, M., \& Setiawan, T. 2018. Sistem Informasi Manajemen. Surabaya: TS Publisher.

Mukarromah, S., Maro'ah, S., \& Mochklas, M. 2018. Implementasi Strategi Bauran Pemasaran Dalam Meningkatkan Volume Penjualan Toko Baju Senam Grosir.Com. Jurnal EKSEKUTIF, 15(2): 316333

Nurcahyo, F. (2016). Pengaruh Bauran Pemasaran Terhadap Volume Penjualan Pada Restoran MCDonald's Delta Plaza Surabaya. Jurnal Ilmu dan Riset Manajemen ISSN : 2461-0593 , 5, 4.

Riduwan. (2009). Pengantar Statiska. Bandung: Alfabeta.

Salindeho, A. (2014). Pengaruh Saluran Distribusi Dan Harga Terhadap Peningkatan Volume Penjualan Pada PT. Fastrata Buana, Tbk. Ilmu dan Riset Manajemen, 3, 9.

Sudaryono. (2016). Manajemen Pemasaran Teori dan Implementasi (1 ed.). Yogyakarta: CV. Andi Offset.

Suddin, F. (2013). Pengaruh Bauran Pemasaran Terhadap Volume Penjualan Produk Ayam Pedaging Di Kota Makassar. Ilmu dan Industri Peternakan ISSN : 2355$0732,1,1$. 
Balance Vol. XVI No. 1 | Januari 2019

Sugiyono. (2011). Metode Penelitian Kuantitatif, Kualitatif, dan $R \& D$. Bandung: CV. AFABETA.
Swastha dan Irawan. (2008). Manajemen Pemasaran Modern. Yogyakarta: Liberty.

Tjiptono. (2008). Strategi Pemasaran (3 ed.). Yogyakarta: ANDI. 